\title{
Breastfeeding Initiation Among Women With Preeclampsia With Severe Features Superimposed on Diabetes Mellitus
}

\author{
Leandro Cordero, $M D^{1^{*}}$, Michael $R$ Stenger, $M D^{1}$, Mark $B$ Landon, $M D^{2}$ and Craig $A$ \\ Nankervis, $M D^{1}$
}

${ }^{1}$ Department of Pediatrics, The Ohio State University, USA

${ }^{2}$ Department of Obstetrics and Gynecology, The Ohio State University, USA

*Corresponding author: Leandro Cordero, MD, Professor Emeritus, Department of Pediatrics, The Ohio State University Wexner Medical Center, N118 Doan Hall, 410 W. 10 ${ }^{\text {th }}$ Avenue, Columbus, Ohio, USA, 43210-1228, Tel: 614-293-8660, Fax: 614-293-7676

\begin{abstract}
Background: Timely delivery and magnesium sulfate $\left(\mathrm{MgSO}_{4}\right)$ remain mainstays in the treatment of preeclampsia with severe features (PSF) which may be superimposed on preexisting conditions such as diabetes mellitus (PDM). Preeclampsia associated with premature delivery, severity of condition and mother-infant separation increase the risk of breastfeeding (BF) initiation failure.

Objective: To compare BF initiation among 158 women with late-onset PSF with 111 women with PDM all of whom received postpartum $\mathrm{MgSO}_{4}$.

Methods: Retrospective cohort study of women with PSF and PDM without major fetal malformations who delivered at $\geq 34$ weeks GA. PDM group was composed of 33 gestational, 55 Type 1 and 22 Type 2 diabetics. Infant feeding preference declared prenatally was either BF, formula feeding (FF) or both. At discharge, exclusive BF was by direct $\mathrm{BF}$ alone or $\mathrm{BF}$ complemented with expressed breast milk (EBM), whereas formula supplementation defined partial BF, differences were statistically significant at $p<0.05^{*}$.
\end{abstract}

Results: PSF and PDM groups were similar in age, race, and late preterm delivery (73 vs. $66 \%$ ), however, differed in primiparity (65 vs. $45 \%)^{*}$, vaginal deliveries (58 vs. $\left.31 \%\right)^{*}$, repeat cesarean (12 vs. $30 \%)^{*}$, admission to the NICU (44 vs. $58 \%)^{*}$ and neonatal hypoglycemia (20 vs. $\left.41 \%\right)^{*}$. Both groups were similar in prior BF experience (17 vs. $22 \%$ ) and in intention to BF ( 80 vs. $71 \%$ ), intention to FF (16 vs. $18 \%)$ or intention to partially BF ( $4 \& 11 \%$ ). At the time of discharge, the rate of exclusive BF among PSF was higher (37 vs. $18 \%)^{*}$, the rate of FF was lower ( 30 vs. $\left.46 \%\right)^{*}$ while the rate of partial BF was similar (33 vs. $36 \%$ ) to those in the
PDM group. Thus, BF initiation (exclusive plus partial BF) occurred in $70 \%$ of PSF and in $54 \%$ of PDM*.

Conclusion: BF initiation rates for women with PDM were significantly lower than those for women with PSF alone. Although intention to BF was similar to that of the general maternal population, BF initiation rates were suboptimal for the PSF group and even lower and more concerning for the PDM group. Direct BF alone or combined with EBM, led to the exclusive provision of human milk during hospitalization to infants in both groups. Women with PSF and PDM represent groups that will require novel and targeted interventions to improve BF initiation rates.

\section{Keywords}

Preeclampsia with severe features, Diabetes Mellitus, Breastfeeding initiation

\section{Background}

Hypertensive disorders affect up to 10 percent of pregnancies and constitute one of the leading causes of maternal and perinatal mortality across the world [1-3]. Preeclampsia is a complication of pregnancy characterized by new onset hypertension and proteinuria occurring after 20 weeks gestation $[3,4]$. Preeclampsia affects between 2 to $8 \%$ of pregnant women in developed countries and is classified as early-onset ( 20 to 33 weeks gestation), late-onset ( $\geq 34$ weeks gestation) or postpartum [5,6]. Early-onset preeclampsia, albeit less common, carries the most severe maternal and perinatal morbidity whereas the more common late-onset

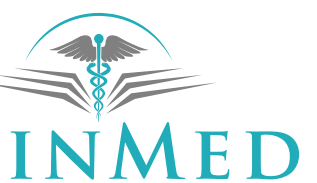

INTERNATIONAL LIBRARY

Citation: Cordero L, Stenger MR, Landon MB, Nankervis CA (2020) Breastfeeding Initiation Among Women With Preeclampsia With Severe Features Superimposed on Diabetes Mellitus. Int J Womens Health Wellness 6:115. doi.org/10.23937/2474-1353/1510115

Accepted: November 12, 2020: Published: November 14, 2020

Copyright: (c) 2020 Cordero L, et al. This is an open-access article distributed under the terms of the Creative Commons Attribution License, which permits unrestricted use, distribution, and reproduction in any medium, provided the original author and source are credited. 
preeclampsia is also responsible for significant adverse maternal and neonatal outcomes [5-9].

According to well defined clinical and laboratory criteria, late-onset preeclampsia can be defined as preeclampsia with severe features (PSF) which may be superimposed on preexisting conditions such as diabetes mellitus (PDM) [1-3]. PSF can lead to maternal complications such as pulmonary edema, myocardial infarction, stroke, adult respiratory distress syndrome, coagulopathy, renal failure and retinal injury $[4,10,11]$. Adverse neonatal outcomes for women with PSF include intrauterine growth restriction, uteroplacental insufficiency and prematurity while for women with PDM, outcomes such as macrosomia, hypoglycemia and admission to the neonatal intensive care unit (NICU) are more frequent $[5,10,11]$.

The definitive treatment for PSF and PDM remains delivery which often precipitates indicated preterm birth $[3,4,10,11]$. Another mainstay in the treatment of women with PSF or PDM is 24-hour postpartum administration of magnesium sulfate $\left(\mathrm{MgSO}_{4}\right)$ for seizure prophylaxis $[1-3,7]$. While serious maternal and neonatal side effects of $\mathrm{MgSO}_{4}$ are rare, this therapy in addition to the condition of the mother and her often premature infant may lead to mother-infant separation during the critical first postpartum day [12-14].

Breastfeeding (BF) should be considered a desirable maternal and neonatal outcome as it is key to the shortand long-term health and wellbeing of mothers and their infants $[15,16]$. In addition to traditionally recognized barriers to BF among healthy women, maternal and neonatal morbidities that complicate PSF or PDM may also interfere with or delay BF initiation and/or BF duration $[6-9,17,18]$. While long term cardiovascular and metabolic effects of PSF and PDM on women and their infants $[4,10,11]$ have been described, reports on BF initiation among women with PSF and PDM remain limited [6,7,17-19].

\section{Objective}

To compare BF initiation among 158 women with late-onset PSF with 111 women with PDM all of whom received postpartum $\mathrm{MgSO}_{4}$.

\section{Subjects and Methods}

This retrospective cohort investigation was approved by the Institutional Review Board at The Ohio State University Wexner Medical Center. Electronic maternal and neonatal records (2013-18) were reviewed. Women with late-onset PSF or PDM were diagnosed according to established clinical and laboratory criteria [1-3,20,21]. Prepregnancy body mass index (BMI) was used to classify women as obese (BMI $29-34 \mathrm{~kg} / \mathrm{m}^{2}$ ), very obese (35$\left.39 \mathrm{~kg} / \mathrm{m}^{2}\right)$ or extremely obese $\left(\geq 40 \mathrm{~kg} / \mathrm{m}^{2}\right)$.

The study population consisted of women with PSF and PDM (a group that included gestational, Type 1 and
Type 2 diabetics) and their singleton infants if delivered at $\geq 34$ weeks gestation. Pregnancies affected by major malformations were excluded. Upon arrival to labor and delivery, each woman reported her past BF experience and her intended infant feeding choice. Our family-centered care system has rooming-in available and full-time lactation consultants whose services are offered to all women regardless of their infant feeding preference.

Per our hospital practice, symptomatic infants were transferred from the delivery room to the NICU for further care. Following delivery if the condition of the mother and her infant allowed, maternal-infant interactions such as holding, skin-to-skin contact, and BF were encouraged. Asymptomatic infants able to feed were transferred to the newborn nursery for routine care and glucose monitoring if indicated. Delivery room and postpartum maternal-infant interactions were observed and documented by the obstetrical, newborn nursery and NICU nursing staffs and by lactation consultants.

Screening for hypoglycemia (blood glucose $<40 \mathrm{mg}$ / dl) was done via serial point of care testing (Accu-Chek ${ }^{\circ}$ ) or by plasma glucose measurement in the laboratory (Beckman Coulter AU5800, Beckman Coulter Inc., Brea, CA, U.S.A.) starting within the first two hours of life or after the first feeding and every 2-4 hours thereafter as needed. Asymptomatic infants in the newborn nursery with hypoglycemia were BF or FF and those with recurrent hypoglycemia were treated with intravenous (IV) dextrose. On admission to the NICU, most infants were started on IV dextrose and those who were able to feed were BF or FF.

Exclusive BF was defined by direct feedings from the breast, by expressed breast milk (EBM) alone or in combination with direct BF or donor human milk (DHM). Partial BF was defined by the initiation of formula supplementation. BF was considered early if it occurred within 2 hours from birth. BF initiation was defined as any BF by exclusive and partial BF combined during the last 24 hours preceding hospital discharge. Due to the retrospective study design, no follow-up information was available on infant feeding practices after hospital discharge.

\section{Statistical Analysis}

Comparisons between women with PSF and PDM were made with two-sample t-tests for continuous variables and Chi square tests for categorical variables. Significance was established at a $p$ value $<0.05$. A secondary analysis was designed to ascertain BF outcomes based on prior BF experience in each of the preeclampsia groups.

\section{Results}

The study population consisted of 158 women with PSF and 111 women with PDM, 33 with gestational diabetes mellitus (GDM), 55 with Type 1 and 23 with Type 2 pregestational diabetes mellitus (PGDM) all of whom 
Table 1: Comparison of women with preeclampsia with severe features with and without diabetes.

\begin{tabular}{|c|c|c|c|}
\hline & Severe Features (PSF) & $\begin{array}{l}\text { Severe Features with Diabetes } \\
\text { Mellitus (PDM) }\end{array}$ & $p$ \\
\hline Mother-Infant dyads no. & 158 & 111 & \\
\hline Mothers age $(\mathrm{y})$ mean $\pm \mathrm{SD}$ & $29 \pm 6$ & $30 \pm 6$ & NS \\
\hline \multicolumn{4}{|l|}{ Race } \\
\hline Black no. (\%) & $37(23)$ & $30(27)$ & NS \\
\hline White no. (\%) & $99(63)$ & $61(55)$ & NS \\
\hline Hispanic no. (\%) & $12(8)$ & $12(11)$ & NS \\
\hline Other no. (\%) & $10(6)$ & $8(7)$ & NS \\
\hline Chronic hypertension no. (\%) & $0(0)$ & $43(39)$ & 0.0001 \\
\hline $\mathrm{BMI} \mathrm{kg} / \mathrm{m}^{2}$ mean $\pm \mathrm{SD}$ & $30 \pm 8$ & $37 \pm 9$ & 0.0001 \\
\hline BMI kg/m² $\geq 35$ no. (\%) & $39(25)$ & $55(50)$ & 0.0001 \\
\hline Primiparous no. (\%) & $103(65)$ & $50(45)$ & 0.001 \\
\hline \multicolumn{4}{|l|}{ Mode of Delivery } \\
\hline Vaginal no. (\%) & $91(58)$ & $34(31)$ & 0.0001 \\
\hline Primary cesarean no. (\%) & $48(30)$ & $43(39)$ & NS \\
\hline Repeat cesarean no. (\%) & $19(12)$ & $34(30)$ & 0.0003 \\
\hline Mother length of stay $(d)$ mean $\pm S D$ & $5 \pm 1$ & $5 \pm 2$ & NS \\
\hline
\end{tabular}

received postpartum $\mathrm{MgSO}_{4}$ for seizure prophylaxis. Women with gestational diabetes were younger $(29 \mathrm{y})$ than those with Type $1(34 \mathrm{y})$ and Type $2(39 \mathrm{y})$ diabetes ( $p$ 0.001). Race distribution was similar between the sub-groups except that white women were more common among Type 1 patients. BMI $\geq 35$ was observed among $42 \%$ of gestational, $47 \%$ of Type 1 and $51 \%$ of Type 2 women $(p<0.001)$. Chronic hypertension (CHTN) affected $48 \%$ of gestational, $27 \%$ of Type 1 and $57 \%$ of Type 2 diabetics ( $p$ 0.03). Mode of delivery was similar across the groups, where one third were vaginal and two thirds cesarean delivery. Mean gestational age at delivery (36 \pm 1 week) and the rate of late premature delivery (61 vs. $76 \%$ ) were similar. Significantly, mean birth weight was lower among gestational $(2710 \mathrm{~g})$ than among Type $1(3334 \mathrm{~g})$ and Type $2(3176 \mathrm{~g})$ diabetics ( $p$ $<0.0001$ ). Admission to the NICU was required for $58 \%$ of infants of gestational, $64 \%$ of Type 1 and $48 \%$ of Type 2 diabetics. All mothers and infants from the PSF and PDM groups were discharged in good health.

\section{Comparison of women with preeclampsia with se- vere features with and without diabetes}

Clinical and demographic characteristics of women with PSF and those with PDM are shown in Table 1. Most variables were similar although primiparity and rate of vaginal delivery were greater in the PSF group. $\mathrm{BMI}$ and rate of repeat cesarean delivery were higher in the PDM group. Indications for primary cesarean (failed induction of labor $20 \%$, non-reassuring fetal wellbeing $30 \%$, worsening hypertension $23 \%$, malpresentations $16 \%$ and miscellaneous $11 \%$ ) were similar among the groups. Consistent with the diagnosis and treatment of PSF and PDM, all women received 24-hour postpartum $\mathrm{MgSO}_{4}$. Additional antihypertensive medications were given to $26 \%$ of women in the PSF and in $66 \%$ of women in the PDM group $(p<0.01)$. CHTN was present in $43(39 \%)$ of women in the PDM group but none of the women in the PSF group $(p<0.01)$.

\section{Neonatal outcomes of infants born to women with preeclampsia with severe features with and without diabetes}

Neonatal outcomes of infants born to women with PSF and PDM are shown in Table 2. The PSF and PDM groups were similar in gestational age (36 \pm 1 week), rate of late prematurity (73 vs. $66 \%$ ), length of hospital stay ( 6 vs. $6 \mathrm{~d}$ ) and being discharged home concurrently with their mothers (70 vs. $69 \%$ ). Large for gestation infants were more common in the PDM group (34 vs. $11 \%)$ while small for gestation infants were more common in the PSF group (22 vs. $10 \%)(p<0.001)$. Neonatal hypoglycemia (41 vs. $20 \%$ ) and admission to the NICU (58 vs. $44 \%$ ) were more common in the PDM group ( $p<$ 0.001 and 0.04 , respectively).

Of the infants admitted to the NICU, $89 \%$ of the PSF and $81 \%$ of the PDM were late preterm. Comparison of NICU admission diagnoses between PSF and PDM groups showed a similar incidence of respiratory distress (33 vs. $24 \%$ ), apnea-bradycardia-cyanosis (11 vs. $10 \%)$, temperature instability-hypotonia-poor feeding ( 26 vs. $14 \%$ ) and miscellaneous (7 vs. $8 \%$ ). Hypoglycemia was the most common diagnosis (44 vs. $23 \%$ ) among infants of the PDM group.

Prior BF experience and early BF among women with preeclampsia with severe features with and without diabetes

All women remained in labor and delivery for the 
first 24-hours postpartum for $\mathrm{MgSO}_{4}$ administration. Skin-to-skin contact and the rate of early $\mathrm{BF}$ during the first 2 postpartum hours were similar among the PSF and PDM groups (Table 3).

Further analysis of the influence of mode of delivery on the PSF group showed that 29 of 91 (32\%) women who delivered vaginally and 11 of 67 (16\%) who delivered by section $\mathrm{BF}$ their infants during the first two postpartum hours $(p<0.02)$. Among women in the PDM group, 13 of 34 (38\%) who delivered vaginally and 7 of 77 (9\%) who delivered by section BF their infants during the first two postpartum hours $(p<0.001)$. However, within 6 hours from birth, the influence of mode of delivery on the time to first BF for either group was similar.

There were fewer multiparous women in the PSF than in the PDM group, although prior BF experience was more common in the PSF group (69\%) compared to the PDM group (48\%, p 0.02). Breastfeeding initiation among women with prior BF experience was $68 \%$ in the PSF and $69 \%$ in the PDM group. Among multiparous women with no prior $\mathrm{BF}$ experience, any $\mathrm{BF}$ was recorded for $12 \%$ in the PSF and $30 \%$ in the PDM group.

\section{Intention to BF and BF at discharge for women with preeclampsia with severe features with and without diabetes}

Intention to $\mathrm{BF}$ ( 80 vs. $71 \%$ ), intention to $\mathrm{FF}$ ( 16 vs. $18 \%$ ) and intention to $\mathrm{BF}$ and $\mathrm{FF}$ (4 vs. $11 \%$ ) were similar between the PSF and PDM groups (Table 4). At the time of discharge the rate of exclusive BF among PSF was higher ( 37 vs. $18 \%, p$ 0.001), the rate of FF was lower

Table 2: Neonatal outcomes of infants born to women with preeclampsia with severe features with and without diabetes.

\begin{tabular}{|c|c|c|c|}
\hline & Severe Features (PSF) & $\begin{array}{l}\text { Severe Features with Diabetes } \\
\text { Mellitus (PDM) }\end{array}$ & $p$ \\
\hline Mother-Infant dyads no. & 158 & 111 & \\
\hline Gender (males) no. (\%) & $74(47)$ & $62(56)$ & NS \\
\hline Birthweight $(\mathrm{g})$ mean \pm SD & $2582 \pm 587$ & $3120 \pm 739$ & 0.001 \\
\hline Gestational age $(w)$ mean \pm SD & $36 \pm 1$ & $36 \pm 1$ & NS \\
\hline Gestational age 34 weeks no. (\%) & $30(19)$ & $17(15)$ & NS \\
\hline Gestational age 35 weeks no. (\%) & $41(26)$ & $23(21)$ & NS \\
\hline Gestational age 36 weeks no. (\%) & $44(28)$ & $33(29)$ & NS \\
\hline All preterm no. (\%) & $115(73)$ & $73(66)$ & NS \\
\hline Full-term no. (\%) & $43(27)$ & $38(34)$ & NS \\
\hline \multicolumn{4}{|l|}{ Intrauterine Growth } \\
\hline Appropriate for gestational age no. (\%) & $106(67)$ & $62(56)$ & NS \\
\hline Large for gestational age no. (\%) & $17(11)$ & $38(34)$ & 0.0001 \\
\hline Small for gestational age no. (\%) & $35(22)$ & $11(10)$ & 0.008 \\
\hline Admission to NICU no. (\%) & $70(44)$ & $64(58)$ & 0.04 \\
\hline Neonatal hypoglycemia no. (\%) & $32(20)$ & $46(41)$ & 0.0002 \\
\hline Infant length of stay $(d)$ mean $\pm S D$ & $6 \pm 6$ & $6 \pm 6$ & NS \\
\hline Discharged home with mother no. (\%) & $110(70)$ & $77(69)$ & NS \\
\hline
\end{tabular}

Table 3: Prior BF experience and early BF among women with preeclampsia with severe features with and without diabetes.

\begin{tabular}{|l|l|l|l|}
\hline & Severe Features (PSF) & $\begin{array}{l}\text { Severe Features with Diabetes } \\
\text { Mellitus (PDM) }\end{array}$ & $p$ \\
\hline Mother-Infant dyads no. & 158 & 111 & 0.001 \\
\hline Primiparous no. (\%) & $103(65)$ & $50(45)$ & 0.001 \\
\hline Multiparous no. (\%) & $55(35)$ & $61(55)$ & 0.02 \\
\hline$\quad$ Prior breastfeeding no. (\%) & $38(69)$ & $29(48)$ & \\
\hline Time to First Breastfeeding & & & NS \\
\hline$<1$ hour no. (\%) & $29(18)$ & $16(14)$ & NS \\
\hline $1-2$ hours no. (\%) & $11(7)$ & $4(4)$ & NS \\
\hline $3-6$ hours no. (\%) & $24(15)$ & $8(7)$ & NS \\
\hline $7-24$ hours no. (\%) & $30(19)$ & $33(30)$ & NS \\
\hline$\geq 25$ hours no. (\%) & $33(21)$ & $32(29)$ & NS \\
\hline Never breastfed no. (\%) & $31(20)$ & $86(77)$ & NS \\
\hline Received lactation consult no. (\%) & $138(87)$ & \\
\hline
\end{tabular}


Table 4: Intention to BF and BF at discharge for women with preeclampsia with severe features with and without diabetes.

\begin{tabular}{|l|l|l|l|}
\hline & Severe Features (PSF) & $\begin{array}{l}\text { Severe Features with } \\
\text { Diabetes Mellitus (PDM) }\end{array}$ & $p$ \\
\hline Mother-Infant dyads no. & 158 & 111 & NS \\
\hline Prior Breastfeeding no. (\%) & $27(17)$ & $23(22)$ & NS \\
\hline Mother-Infant Feeding Preference & & $79(71)$ & NS \\
\hline$\quad$ Intention to breastfeed no. (\%) & $127(80)$ & $12(11)$ & NS \\
\hline Intention to feed both no. (\%) & $6(4)$ & $20(18)$ & 0.001 \\
\hline Intention to feed formula no. (\%) & $25(16)$ & NS \\
\hline Infant Feeding at Discharge & & $20(18)$ & NS \\
\hline Exclusive total no. (\%) & $58(37)$ & $8(40)$ & NS \\
\hline Direct BF no. (\%) & $25(43)$ & $4(20)$ & NS \\
\hline Direct BF \& Expressed breast milk no. (\%) & $17(29)$ & $8(40)$ & NS \\
\hline Expressed breast milk no. (\%) & $16(28)$ & $40(36)$ & NS \\
\hline Partial total no. (\%) & $52(33)$ & $19(48)$ & NS \\
\hline Direct BF \& Formula no. (\%) & $28(54)$ & $9(23)$ & 0.01 \\
\hline Direct BF, Expressed breast milk \& Formula no (\%) & $14(27)$ & $12(30)$ & 0.01 \\
\hline Expressed breast milk \& Formula no. (\%) & $10(19)$ & $51(46)$ & $60(54)$ \\
\hline Formula feeding no. (\%) & $48(30)$ & $110(70)$ & \\
\hline Any breastfeeding no. (\%) & & \\
\hline
\end{tabular}

( 30 vs. $46 \%, p$ 0.01) while partial BF was similar ( 33 vs. $36 \%$ ). Thus, BF initiation (any BF) occurred in $70 \%$ of PSF and in $54 \%$ of PDM $(p<0.01)$.

Exclusive $B F$ at discharge resulted from direct $B F$ or from direct $B F$ with $E B M$ or from EBM alone in both preeclampsia groups. Twenty-nine of $58(50 \%)$ infants in the PSF group and 12 of $20(60 \%)$ in the PDM group that fed exclusive human milk at the time of discharge received formula supplementation during their hospital stay. Sixteen (10\%) infants in the PSF group and $6(5 \%)$ in the PDM group received DHM during their hospital stay.

There were 127 women from the PSF group and 79 from the PDM group who antenatally intended to BF and who at discharge BF exclusively (43 vs. $25 \%$ ), BF partially ( 39 vs. $46 \%$ ) and FF (18 vs. $29 \%$ ). Of 18 women (6 from the PSF group and 12 from PDM group) who antenatally intended to $\mathrm{BF}$ and $\mathrm{FF}$, at the time of discharge, 11 $\mathrm{FF}, 4 \mathrm{BF}$ partially and $3 \mathrm{BF}$ exclusively. Of the 25 women from the PSF and 20 from the PDM group who prenatally declared their intention to FF at discharge all but one FF. There were 43 of 111 (39\%) women from the PDM group who also had CHTN, this sub-group compared to the 68 PDM without CHTN showed lower intention to $\mathrm{BF}$ ( 59 vs. $79 \%, p 0.02$ ) and higher FF at discharge ( 58 vs. $38 \%, \mathrm{p} 0.03)$.

\section{Discussion}

The incidence of preeclampsia complicating pregnancies remains constant around the world [1-4,11] and its successful management is often based on indicated early delivery which continues to result in a high rate of premature births $[4,5]$. Thus, it may be anticipated that NICU admissions will remain high especially for infants born to women with PSF alone or superimposed on preexisting conditions such as CHTN or diabetes mellitus [6-9,21,22]. Prematurely born infants are challenged by a myriad of developmental obstacles and illnesses that could affect initiation and continuation of BF [7-9,23-25]. Women affected by GDM or PGDM and their infants experienced morbidities and co-morbidities unique to their condition that may explain fewer vaginal deliveries, obesity, fetal macrosomia, neonatal hypoglycemia, and increased admissions to the NICU $[8,9,25,26]$. Additionally, admission to the NICU, even if temporary, diminishes opportunities for critical physiological mother-infant interactions, while creating anxiety and negative emotions in the mother $[7,13,26,27]$. Pregnant women with diabetes, especially with PGDM, have concerns about their own health and that of their unborn child and when preeclampsia develops, this additional stressor further challenges their emotional well-being [28].

Despite the heterogeneity of morbidities and co-morbidities associated with high risk obstetrical pregnancies, intention to $\mathrm{BF}$, a strong predictor of $\mathrm{BF}$ initiation, remains similar to that of the general maternal population $[6-9,29,30]$. While intention to BF was similar, there was a discordance between intention to $\mathrm{BF}$ and the rate of exclusive or partial BF at discharge [7-9,31]. In 2015, approximately $83 \%$ of the general maternal population in the U.S. initiated breastfeeding at discharge from the hospital [30]. In contrast, the rate of BF initiation for the PSF group (70\%) is suboptimal, while the rate for the PDM group (54\%) is even lower and more concerning.

Regardless of health or medical conditions, pre- 
eclampsia is more common in primiparous women. Multiparous women in the PDM group had less prior BF experience than multiparous women in the PSF group. Recently, we reported that multiparous women with PGDM without prior BF experience constituted a group at higher risk of BF initiation failure [32]. We assumed in both investigations that multiparous women who declared no prior BF experience had either not intended to $\mathrm{BF}$ or had attempted to BF and were unsuccessful.

In normal as well as in high risk pregnancies certain hospital practices may delay infant feeding (i.e., cesarean delivery, eye prophylaxis, vitamin $\mathrm{K}$ administration, blood glucose monitoring). While some of these practices may be postponed others may be unavoidable especially in infants born to women with PDM who are at greater risk for hypoglycemia [6-9,22]. It has been well established that early BF or, if BF is not possible, FF may prevent or correct hypoglycemia and increase BF initiation at discharge from the hospital $[25,27,33]$. When hypoglycemia persists, transfer of the infant to the NICU is required and maternal-infant separation becomes unavoidable [26].

Cesarean delivery, a traditionally recognized obstacle to early mother infant interactions, remains consistently high among women with PSF and even higher among those with PDM [7,34]. Cesarean birth is known to prevent or delay skin-to-skin contact, reduce the incidence of early BF and increase the likelihood of formula supplementation [12,25,32-36]. The lower BF rates we observed following cesarean delivery among PSF and PDM women compared to vaginal birth highlight the severity of the mother's illnesses and/or their infant morbidities and may contribute to BF initiation failure. The major disruption in mother-infant contact following birth arose from the need for immediate transfer of symptomatic prematurely born infants to the NICU.

The efficacy of magnesium sulfate given postpartum to prevent seizures in women with PSF and PDM is well established [1-4]. Unfortunately, effects on the mothers' sensorium during the infusion make mother-infant separation more common [14]. The number of women who had skin-to-skin contact and/or BF during the first postpartum day in the PSF and PDM groups attest to hospital practices that include close monitoring of mothers and infants with complex conditions at the delivery room and adjacencies $[26,27]$. Delays in mother-infant interactions are common following the delivery of women with PSF and PDM as shown by the fact that less than $25 \%$ were able to BF or have skin-to-skin contact with their infants during the first two postpartum hours.

Both the American Academy of Pediatrics and the Academy of Breastfeeding Medicine strongly recommend exclusive BF for all healthy infants during birth hospitalization and beyond [24,37-39]. However, these organizations wisely acknowledge that other nutritional options may be needed to temporarily replace or supplement BF under well-defined circumstances (i.e., late preterm infants). Healthcare providers must be aware that delays associated with some morbidities will further the need for alternatives to direct BF [24,37,39]. Due to their clinical condition not all women with PSF or PDM are able to BF shortly after birth. In that case, our practice is to provide mother's milk, if obtained antenatally, EBM if tolerated, DHM if feasible or infant formula if prescribed by a physician $[24,40,41]$.

It is well established that milk expression by hand or with an electrical pump may help mothers overcome obstacles to successful BF and therefore increase BF duration $[42,43]$. Our finding that women with PSF or PDM who intended to BF had a BF initiation (exclusive or partial BF) rate of 82 and $71 \%$, respectively, is significant because it compares well with that of the general maternal population [30]. However, this success is tempered by the fact that only $43 \%$ of women in the PSF group and $25 \%$ of women in the PDM group who antenatally intended to BF exclusively BF their infants at the time of discharge. In line with current literature, we hoped that women with direct BF with or without EBM at discharge would continue to provide exclusive or partial BF [41-44]. Women in either preeclampsia group who BF exclusively with EBM without any direct BF is concerning since available literature is pessimistic about BF duration in these cases [23,45-49]. Several investigators cautioned that exclusive EBM feeding should be recommended for full-term and premature infants only when medically necessary and not as a substitute for feeding directly from the breast $[47,48]$. On the other hand, some authors suggest that early initiation of EBM after delivery has been shown to increase milk production among mothers of very low birth weight infants and that EBM in conjunction with direct BF could be beneficial $[43,44]$.

The data on partial BF (direct BF or EBM with formula) raises similar concerns about BF duration following discharge, but it is possible that with support and guidance, this feeding modality could potentially evolve into exclusive BF. Earlier investigators, however, noted that EBM alone, without directly BF at 3 days postpartum could associate with shorter BF duration [50]. More recently, other authors reported that pumping without feeding at the breast is associated with shorter milk feeding duration and early introduction of formula as compared to feedings at the breast with or without pumping $[49,51]$. We agree with Keim, et al. [49] in that some dyads that cannot feed at the breast initially, an eventual transition is possible and should be encouraged $[49,52]$.

Limitations to this investigation are those inherent to the retrospective design and the lack of follow-up information regarding infant feeding after discharge. Also, the definition of BF initiation at discharge may be 
applicable only to women with high risk obstetrical conditions for whom early mother-infant contact may be delayed. The strength of this investigation rests on the size of the obstetrical and neonatal population and the fact that the data were obtained directly from medical records, not via post-delivery maternal questionnaires.

In conclusion, traditionally recognized obstacles to BF initiation appeared to affect both groups, however, several were more common in the PDM group where women were more often multiparous without prior BF experience, obese, had fewer vaginal deliveries, more CHTN, neonatal hypoglycemia and admissions to the NICU. Although intention to BF was similar, BF initiation rates for both the PSF and PDM groups were below that of the general maternal population with the BF initiation rate for the PDM group particularly concerning. Women with PSF and PDM represent groups that will require novel and targeted interventions to improve $B F$ initiation rates.

\section{References}

1. American College of Obstetricians and Gynecologists; Task Force on Hypertension in Pregnancy (2013) Hypertension in pregnancy. Report of the american college of obstetricians and gynecologists' task force on hypertension in pregnancy. Obstet Gynecol 122: 1122-1131.

2. Brown MA, Magee LA, Kenny LC, Karumanchi SA, McCarthy FP, et al. (2018) The hypertensive disorders of pregnancy: ISSHP classification, diagnosis \& management recommendations for international practice. Pregnancy Hypertens 13: 291-310.

3. ACOG Practice Bulletin No. 202 Summary: Gestational hypertension and preeclampsia (2019) Obstet Gynecol 133: 211-214.

4. Chappell LC, Brocklehurst P, Green ME, Hunter R, Hardy $P$, et al. (2019) Planned early delivery or expectant management for late preterm pre-eclampsia (PHOENIX): A randomized controlled trial. Lancet 394: 1181-1190.

5. Lisonkova S, Joseph KS (2013) Incidence of preeclampsia: Risk factors and outcomes associated with early-versus late-onset disease. Am J Obstet Gynecol 209: 544.e1-544. e2.

6. Burgess A, McDowell W, Ebersold S (2019) Association between lactation and postpartum blood pressure in women with preeclampsia. MCN Am J Matern Child Nurs 44: 86-93.

7. Cordero L, Valentine CJ, Samuels P, Giannone PJ, Nankervis CA (2012) Breastfeeding in women with severe preeclampsia. Breastfeed Med 7: 457-463.

8. Cordero L, Gabbe SG, Landon MB, Nankervis CA (2013) Breastfeeding initiation in women with gestational diabetes mellitus. J Neonatal Perinatal Med 6: 303-310.

9. Cordero L, Thung S, Landon MB, Nankervis CA (2014) Breast-feeding initiation in women with pregestational diabetes mellitus. Clin Ped 53: 18-25.

10. Bokslag A, van Weissenbruch M, Willem Mol B, de Groot CJM (2016) Preeclampsia; short and long-term consequences for mother and neonate. Early Hum Dev 102: 4750.

11. Fox R, Kitt J, Leeson P, Aye CYL, Lewandowski AJ (2019)
Preeclampsia: Risk factors, diagnosis, management, and the cardiovascular impact on the offspring. J Clin Med 8: 1625.

12. Bystrova K, Ivanova V, Edhborg M, Matthiesen AS, Arvidson ABR, et al. (2009) Early contact versus separation: Effects on mother-infant interaction one year later. Birth 36 : 97-109.

13. Widström AM, Lilja G, Aaltomaa-Michalias $P$, Dahllöf $A$, Lintula M, et al. (2011) Newborn behavior to locate the breast when skin-to-skin: a possible method for enabling early self-regulation. Acta Paediatr 100: 79-85.

14. Abassi-Ghanavati M, Alexander JM, McIntire DD, Savani RC, Leveno KJ (2012) Neonatal effects of magnesium sulfate given to the mother. Am J Perinatol 29: 795-809.

15. Steube AM, Bonuck K (2011) What predicts intent to breastfeed exclusively? Breastfeeding knowledge, attitudes, and beliefs in a diverse urban population. Breastfeed Med 6: 413-420.

16. Gunderson EP, Hurston SR, Ning X, Lo JC, Crites Y, et al. (2015) Lactation and progression to type 2 diabetes mellitus: A prospective cohort study. Ann Intern Med 163: 889898.

17. Leeners B, Rath W, Kuse S, Neumaier-Wagner P (2005) Breast-feeding in women with hypertensive disorders in pregnancy. J Perinat Med 33: 553-560.

18. Ersch J, Baeniger O, Bernet V, Bucher HU (2008) Feeding problems in preterm infants of preeclamptic mothers. $J$ Paediatr Child Health 44: 651-655.

19. Demirci J, Schmella M, Glasser M, Bodnar L, Himes KP (2018) Delayed lactogenesis II and potential utility of antenatal milk expression in women developing late-onset preeclampsia: A case series. BMC Pregnancy and Childbirth 18: 68.

20. Berger H, Gagnon R, Sermer M (2016) Maternal Fetal Medicine Committee. Diabetes in pregnancy. J Obstet Gynecol Can 38: 667-679.

21. ACOG Practice Bulletin No. 203: Chronic Hypertension in Pregnancy (2019) Obstetrics \& Gynecology 133: e26-e50.

22. Backes $\mathrm{CH}$, Markham $\mathrm{K}$, Moorehead $\mathrm{P}$, Cordero L, Nankervis CA, et al. (2011) Maternal preeclampsia and neonatal outcomes. J Pregnancy 2011: 214365.

23. Gianni ML, Bezze E, Sannino P, Stori E, Plevani L, et al. (2016) Facilitators and barriers of breastfeeding late preterm infants according to mothers' experiences. BMC Pediatr 16: 179.

24. Boies EG, Vaucher YE (2016) ABM Clinical Protocol \#10: Breastfeeding the late preterm (34-36 6/7 weeks of gestation) and early term infants (37-38 6/7 weeks of gestation), second revision 2016. Breastfeed Med 11: 494-500.

25. Cordero L, Stenger MR, Landon MB, Nankervis CA (2019) In-hospital formula supplementation and breastfeeding initiation in infants born to women with pregestational diabetes mellitus. J Neonatal Perinatal Med 12: 285-293.

26. Cordero L, Oza-Frank R, Stenger MR, Landon MB, Nankervis CA (2018) Decreasing NICU admissions of asymptomatic infants of women with pregestational diabetes mellitus improves breastfeeding initiation rates. J Neonatal Perinatal Med 11: 155-163.

27. Cordero L, Ramesh S, Hillier K, Giannone PJ, Nankervis CA (2013) Early feeding and neonatal hypoglycemia in infants of diabetic mothers. SAGE Open Med 1: 2050312113516613. 
28. Stern C, Trapp EM, Mautner E, Deutsch M, Lang U, et al. (2014) The impact of severe preeclampsia on maternal quality of life. Qual Life Res 23: 1019-1026.

29. Cordero L, Bajwa A, Prasad MR, Oza-Frank R, Landon MB, et al. (2016) Breastfeeding at hospital discharge among high risk obstetrical patients. Int $\mathrm{J}$ Womens Health Wellness 2: 031.

30. Centers for Disease Control and Prevention (2018) Breastfeeding report card: United States 2018. Atlanta, GA: Centers for Disease Control and Prevention.

31. Kozhimannil KB, Jou J, Attanasio LB, Joarnt LK, McGovern P (2014) Medically complex pregnancies and early breastfeeding behaviors: A retrospective analysis. PLoS One 9: e104820.

32. Cordero L, Stenger MR, Blaney SD, Finneran MM, Nankervis CA (2019) Prior breastfeeding experience and infant feeding at discharge among women with pregestational diabetes mellitus. J Neonatal Perinatal Med 1-8.

33. Chantry CJ, Dewey KG, Peerson JM, Wagner EA, Nommsen-Rivers LA (2014) In-hospital formula use increases early breastfeeding cessation among first-time mothers intending to exclusively breastfeed. J Pediatr 164: 13391345.

34. Prior E, Santhakumaran S, Gale C, Philips LH, Modi N, et al. (2012) Breastfeeding after cesarean delivery: a systematic review and meta-analysis of world literature. Am J Clin Nutr 95: 1113-1135.

35. Moore ER, Bergman N, Anderson GC, Medley N (2016) Early skin-to-skin contact for mothers and their healthy newborn infants. Cochrane Database Syst Rev 11: CD003519.

36. Walweiner S, Müller M, Doster A, Plewniok K, Wallwiener CW, et al. (2016) Predictors of impaired breastfeeding initiation and maintenance in a diverse sample: what is important? Arch Gynecol Obstet 294: 455-466.

37. Wight N, Marinelli KA (2014) Academy of Breastfeeding Medicine. ABM Clinical Protocol \#1: Guidelines for blood glucose monitoring and treatment of hypoglycemia in term and late-preterm neonates, revised 2014. Breastfeed Med 9: 173-179.

38. Hackman NM, Alligood-Percoco N, Martin A, Zhu J, Kjerulff $\mathrm{KH}$ (2016) Reduced breastfeeding rates in first born later preterm and early term infants. Breastfeed Med 11: 119125.

39. Kellams A, Harrel C, Omage S, Gregory C, Rosen-Carole C (2017) ABM Clinical Protocol \#3: Supplementary feedings in the healthy term breastfed neonate, Revised 2017. Breastfeed Med 12: 188-198.

40. AAP committee on nutrition, AAP section on breastfeed- ing, AAP committee on fetus and newborn (2019) Donor Human Milk for the High-Risk Infant: Preparation, Safety, and Usage Options in the United States. Pediatrics 139: e20163440.

41. JCAHO (2018) Specification manual for Joint commission national quality measures (v2018A). Exclusive breast milk feeding during the newborn's entire hospitalization.

42. Win NN, Binns CW, Zhao Y, Scott JA, Oddy WH (2006) Breastfeeding duration in mothers who express breast milk: a cohort study. Int Breastfeed J 1: 28.

43. Flaherman VJ, Hicks KG, Huynh J, Cabana MD, Lee KA (2016) Positive and negative experiences of breast pumping during the first 6 months. Matern Child Nutr 12: 291298.

44. Parker LA, Sullivan S, Krueger C, Mueller M (2015) Association of timing of initiation of breastmilk expression on milk volume and timing of lactogenesis stage II among mothers of very low-birth-weight infants. Breastfeed Med 10: 84-91.

45. Forster DA, Johns HM, McLachlan HL, Moorhead AM, McEgan KM, et al. (2015) Feeding infants directly at the breast during the postpartum hospital stay is associated with increased breastfeeding at 6 months postpartum: A prospective cohort study. BMJ Open 5: e007512.

46. Felice JP, Cassano PA, Rasmussen KM (2016) Pumping human milk in the early postpartum period: Its impact on long-term practices for feeding at the breast and exclusively feeding human milk in a longitudinal survey cohort. Am J Clin Nutr 103: 1267-1277.

47. Pinchevski-Kadir S, Shust-Barequet S, Zajicek M, Leibovich M, Strauss T, et al. (2017) Direct feeding at the breast is associated with breast milk feeding duration among preterm infants. Nutrients 9: 1202.

48. Bai DL, Fong DYT, Lok KYW, Wong JYH, Tarrant M (2016) Practices, predictors and consequences of expressed breast-milk feeding in healthy full-term infants. Public Health Nutrition 20: 492-503.

49. Keim SA, Boone KM, Oza-Frank R, Geraghty SR (2017) Pumping milk without ever feeding at the breast in the Moms2Moms study. Breastfeed Med 12: 422-429.

50. Geraghty SR, Khoury JC, Kalkwarf HJ (2005) Human milk pumping rates of mothers of singletons and mothers of multiples. J Hum Lact 21: 413-420.

51. Jiang B, Hua J, Wang Y, Fu Y, Zhuang Z, et al. (2015) Evaluation of the impact of breast milk expression in early postpartum period on breastfeeding duration: A prospective cohort study. BMC Pregnancy Childbirth 15: 268.

52. Loewenberg Weisband Y, Keim SA, Keder LM, Geraghty SR, Gallo MF (2017) Early breast milk pumping intentions among postpartum women. Breastfeed Med 12: 28-32. 